\title{
Electroacupuncture may help motor recovery in chronic stroke survivors: A pilot study
}

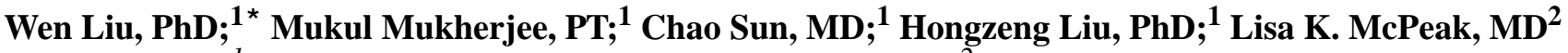 \\ Departments of ${ }^{1}$ Physical Therapy and Rehabilitation Sciences and ${ }^{2}$ Physical Medicine and Rehabilitation, University \\ of Kansas Medical Center, Kansas City, KS
}

\begin{abstract}
Past studies have suggested that acupuncture may reduce spasticity in stroke survivors. We do not know, however, whether acupuncture may enhance the effect of strength training on motor function. This study compared upper-limb motor functional improvement in chronic stroke survivors who received a combination of acupuncture and strength training with that of subjects who received strength training alone. A total of 10 chronic stroke patients with moderate or severe wrist muscle spasticity were recruited for this study. The study used a crossover design with a random order of either combined electroacupuncture and strength training or strength training alone. Each subject received one of the two types of treatment twice a week for the first 6 weeks and switched to the other for another 6 weeks. Quantitative measurements of wrist spasticity, active wrist extension range of motion, isometric wrist strength, and clinical evaluation with Fugl-Meyer (FM) upper-limb motor scores were conducted before and after either treatment. After the combined treatment, the quantitative spasticity level, active wrist extension range of motion (increased by a mean of 16.3 degrees), and FM upper-limb motor score (increased by a mean of 4.9 points) changed significantly $(p<0.01)$ but no significant changes were noted in isometric wrist strength. The strength training alone resulted in no significant changes to any measured variable. The results of the current study indicate that the combined acupuncture and strength training treatment reduced muscle spasticity and may have improved motor function for chronic stroke survivors with moderate or severe muscle spasticity.
\end{abstract}

Key words: acupuncture, electroacupuncture, motor function, muscle spasticity, range of motion, rehabilitation, spasticity, strength training, stroke, wrist strength.

\section{INTRODUCTION}

Acupuncture has been used in stroke rehabilitation in China from ancient times. Results from recent clinical studies, however, have been conflicting. Some past studies have demonstrated the effectiveness of acupuncture treatment in stroke rehabilitation [1-7]. Other studies reported different findings [8-11]. For instance, a recent metaanalysis of past clinical trials in the literature concluded that acupuncture had no additional effect on motor recovery but did have a positive effect on disability [12]. The discrepancy in the literature on the effects of acupuncture treatment in stroke rehabilitation may be partially due to the broadly defined objectives used in past studies. For instance, motor functional recovery after stroke is a motor relearning process. The improvement in motor learning is dependent on the amount of practice [13]. The cortical plasticity that accompanies motor recovery after a brain

Abbreviations: AS = acupuncture and strength training treatment, ASRT $=$ average speed-dependent reflex torque, $\mathrm{FM}=$ Fugl-Meyer, LI = large intestine, ROM = range of motion, $\mathrm{S}=$ strength training treatment, $\mathrm{SI}=$ small intestine, $\mathrm{TW}=$ triple warmer, VASRT = velocity sensitivity of ASRT.

*Address all correspondence to Wen Liu, PhD; Department of Physical Therapy and Rehabilitation Sciences, University of Kansas Medical Center, 3901 Rainbow Blvd, Kansas City, KS 66160; 913-588-4565; fax: 913-588-4568. Email: wliu@kumc.edu

DOI: 10.1682/JRRD.2007.11.0181 
lesion has been shown to depend strongly on training and repetitive practice [14-17]. Acupuncture treatment alone, usually applied while resting, may not bring direct benefits to motor functional recovery.

The effect of acupuncture in stroke rehabilitation may be better demonstrated when a subgroup of people with a specific type of stroke impairment is the target [18]. Existing clinical data, empirical studies, and anecdotal evidence have suggested that acupuncture may release spasticity in individuals after stroke [19-24]. Recent studies indicated that muscle spasticity occurs in only a portion of stroke survivors [25-27]. Acupuncture treatment may be used in this subgroup of stroke survivors to reduce muscle spasticity and probably further improve motor function if used in combination with a motor training program. Muscle weakness is common and has been shown to be a more disabling factor in stroke survivors than spasticity [28-30]. Some past studies have reported a positive effect of strengthening exercises in stroke rehabilitation [31-33]. A combination of acupuncture treatment and strength training may be a better treatment option for stroke survivors with both muscle weakness and spasticity. The question is whether or not acupuncture treatment can result in additional benefit to individuals' motor function when combined with a strength training program.

The purpose of this study was to assess the effect of combined acupuncture and strength training treatment (AS) in a group of chronic stroke survivors based on clinical and quantitative measurements of motor function.

\section{METHODS}

Ten chronic stroke survivors with average age of 60.1 years (range 35-75) were recruited for the study (Table). Each study candidate received an explanation of the study protocol and signed an informed consent prior to participating in the study. All subjects had a documented diagnosis of stroke for more than 2 years, with an average of 7.6 years. The subjects all had a modified Ashworth score of $\geq 3$ in the wrist joint in the baseline measurement. Upper-limb Fugl-Meyer (FM) sensorimotor assessment prior to the start of training revealed a mild motor impairment in one subject, moderate impairment in six subjects, and severe impairment in three subjects (Table).

All subjects participated in a crossover design of two types of treatment: AS and strength training treatment (S) alone. Each treatment lasted for a total of 6 weeks, with two treatment sessions a week on two different days. The order of the two treatments was randomly assigned. The AS phase consisted of 40 minutes of electroacupuncture treatment and 30 minutes of strengthening exercises. The $S$ phase included only the strengthening exercises.

The electroacupuncture protocol was similar to a previous study [21] with some modification, including two more acupressure points and a different stimulation frequency; these modifications were based primarily on the personal experience of a member of the research team who is also a licensed acupuncturist. The areas of skin selected for needling were cleaned with 75 percent alcohol. The needles were single-use, disposable steel acupuncture needles (Seirin, OMS Medical Supplies Inc; Braintree,

Table.

Subject information including age, sex, time poststroke, type of stroke, affected side, and upper-limb Fugl-Meyer motor score at baseline. FuglMeyer motor score indicated different levels of motor impairment. Among them, 3 subjects had baseline motor score $<20$, 6 subjects $20 \geq 50$, and 1 subject $>50$.

\begin{tabular}{lclclcc}
\hline Subject & Age & Sex & Time Poststroke & Type of Stroke & Lesion Side & Fugl-Meyer \\
\hline s1001 & 61 & Male & $5 \mathrm{yr}$ & Hemorrhagic & Right & 26 \\
s1002 & 60 & Male & $4 \mathrm{yr}$ & Embolic & Left & 22 \\
s1003 & 61 & Female & $3 \mathrm{yr}$ & Ischemic & Right & 59 \\
s1004 & 58 & Male & $12 \mathrm{yr}$ & Hemorrhagic & Left & 21 \\
s1005 & 54 & Female & $31 \mathrm{yr}$ & Ischemic & Right & 25 \\
s1006 & 64 & Male & $3 \mathrm{yr} 7 \mathrm{mo}$ & Hemorrhagic & Right & 28 \\
s1007 & 69 & Male & $2 \mathrm{yr} 6 \mathrm{mo}$ & Hemorrhagic & Right & 30 \\
s1008 & 75 & Female & $9 \mathrm{yr}$ & Ischemic & Left & 16 \\
s1009 & 35 & Female & $4 \mathrm{yr}$ & Hemorrhagic & Left & 19 \\
s1010 & 65 & Female & $2 \mathrm{yr}$ & Ischemic & Left & 19 \\
\hline \hline
\end{tabular}


Massachusetts), with a diameter of $0.2 \mathrm{~mm}$ and a length of $60 \mathrm{~mm}$. The needles were inserted into the following acupressure points on the subject's hemiparetic arm: (1) Hegu (large intestine [LI] 4), (2) Houxi (small intestine [SI] 3), (3) Waiguan (triple warmer [TW] 5), (4) Quchi (LI 11), (5) Shousanli (LI 10), and (6) Jianyu (LI 15) (Figure 1). During insertion, the needles were inserted perpendicularly into all six acupuncture points, forming a $90^{\circ}$ angle with the skin surface. Depth of needle insertion was approximately $10 \mathrm{~mm}$ for LI 11 and TW 5 and $15 \mathrm{~mm}$ for all other acupuncture points. After insertion of needles into the tissue, alternating current was passed between the two nearest needles (LI 4 with SI 3, TW 5 with LI 11, and LI 10 with LI 15) with a commercial electroacupuncture device (model ITO-4107, OMS Medical Supplies Inc; Braintree, Massachusetts). Current pulses were set at $2 \mathrm{~Hz}$. The intensity of the current was increased to the point where the patient reported the needling reaction and then it was reduced slightly to an unpleasant but tolerable intensity. The "needling reaction" is the characteristic response of a subject to acupuncture needle insertion and manipulation. The subject reports an acute, strongly aversive sensation that is restricted to the site of needle insertion. After a period of 5 to 10 minutes, when the subject

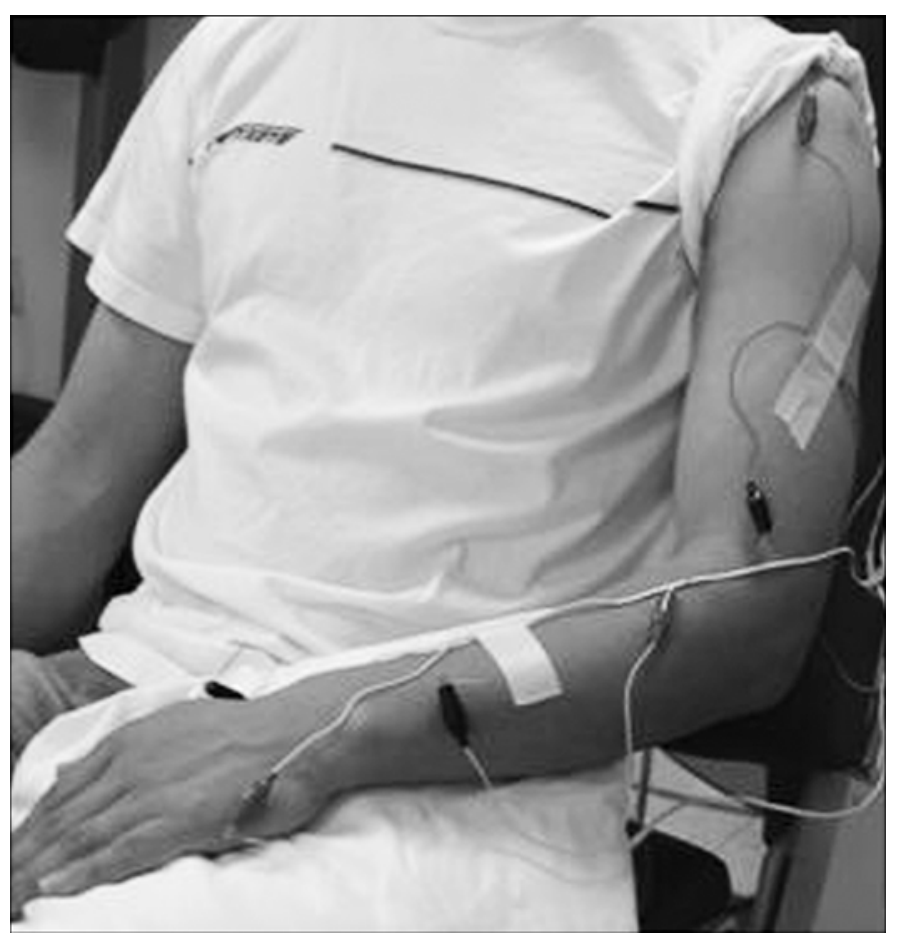

Figure 1.

Illustration of acupuncture needle insertion sites on affected arm. had become sensitized to the stimulus, we increased it slightly and then maintained the current at that level for 30 minutes. We used electroacupuncture rather than manual acupuncture in this study to ensure that all the needle stimuli were handled in the same manner.

During the combined AS phase, subjects performed a strengthening exercise regimen on a Biodex Multi-Joint System 3 Pro (Biodex Medical Systems; Shirley, New York) following the acupuncture treatment. The exercise regimen included active assisted, maximal isokinetic, and maximal isometric exercises. We made the exercises progressively more difficult to perform and increased the subject's required muscle strength and active range of motion (ROM). Strengthening exercises were conducted for about 30 to 45 minutes, with rest periods taken whenever necessary. During the $\mathrm{S}$ phase, subjects performed the same strengthening exercise without the acupuncture treatment.

Subjects were evaluated before (pre) and after (post) each of the two treatments. The posttreatment assessment values for the first treatment phase were taken as the pretreatment assessment values for the second treatment. We measured muscle spasticity at the wrist joint using a quantitative measurement following a previously established procedure [34] with minor modifications. In our procedure, the subject's wrist joint was manipulated passively with the Biodex machine. The test was performed in a sitting position, with the subject strapped into the chair to prevent trunk movement during the experiment. The affected arm of the subject rested on a flat surface that was attached to the subject's chair so that the shoulder was at $0^{\circ}$ of flexion and $10^{\circ}$ to $15^{\circ}$ of abduction. The elbow was positioned at $90^{\circ}$ of flexion. The forearm was strapped onto the resting surface in a prone position. The subject held the hand attachment of the dynamometer so that its axis of rotation aligned with an imaginary line joining the ulnar and the radial styloid processes. The fingers of the subject were strapped around the handle and therefore only the wrist joint was free to move in a vertical plane. Wrist extension movements were made against gravity and flexion movements toward it. Gravity corrections were performed before analyzing the data. The subject's wrist was moved passively through flexion and extension at five different angular velocities: $5^{\circ}, 20^{\circ}, 45^{\circ}, 60^{\circ}$, and $75^{\circ}$. At each velocity, the wrist joint went passively from flexion to extension five times. During the passive wrist movement, the resistance torque and angular motion of the wrist were recorded through transducers in the machine and stored in a computer. Recorded resistive torque at very slow motion of the 
wrist joint at $5 \% \mathrm{~s}$ was taken as the baseline. At each of the following velocities, $20 \% \mathrm{~s}, 45 \% \mathrm{~s}, 60 \%$, and $75 \%$, we determined the average speed-dependent reflex torque (ASRT) as the difference between the resistive torque at each velocity and the baseline. The slope of the regression line for the ASRT values for the four angular velocities was determined as the velocity sensitivity of ASRT (VASRT). Following the spasticity measurement, we measured the isometric muscle strength of wrist extensors and flexors under the same experimental setup. The isometric wrist strength was measured at two wrist positions: neutral and $20^{\circ}$ of flexion. During testing, the Biodex machine was locked at the neutral and $20^{\circ}$ of wrist flexion positions. At each locked joint position, the subject was instructed to perform three trials of maximum isometric flexion and extension contractions. Each contraction lasted for 5 seconds. Short breaks were provided between trials. Muscle forces were recorded from a torque transducer to a computer and stored for later use. The peak muscle forces recorded during each trial of maximum isometric muscle contraction were averaged to obtain the muscle strength.

We measured the active ROM of the wrist joint and index finger using goniometry while the subject tried to actively extend his or her wrist and index finger. We performed the FM assessment for the upper limb following standardized protocols [35]. All tests and strengthening treatments were conducted by the same researcher. Dependent variables in this study included VASRT, wrist joint extension ROM, index finger extension ROM, FM score for the upper limb, and wrist joint isometric strength in flexion and extension. We used paired $t$-tests to determine the effect of both treatments.

\section{RESULTS}

Spasticity measurement data from two of our subjects were excluded from data analysis because of technical problems encountered during data acquisition. The data analysis of spasticity reported here came from the remaining eight subjects. The VASRT values showed a significant $(p<0.05)$ change from $0.0092 \pm 0.0068$ to $0.0068 \pm 0.0057$ after the AS phase (all data presented as mean \pm standard deviation unless otherwise noted). The changes in VASRT values before and after the $\mathrm{S}$ phase were not significant $(p=$ 0.24 ), with a small decrease in mean values from $0.0067 \pm$ 0.0057 to $0.0058 \pm 0.0033$. A previous report included more details on the changes in spasticity [36].
The mean wrist extension ROM values are presented in Figure 2. The baseline value was the mean of the first measurements of all subjects. The pre-AS and post-AS were the means of measurements of all subjects before and after the combined treatment. The pre-S and post-S were the means of measurements of all subjects before and after the strengthening treatment alone. No significant difference was noted between baseline $\left(17.0^{\circ} \pm 19.2^{\circ}\right)$ and pre-AS $\left(20.2^{\circ} \pm 19.8^{\circ}\right)$, but post-AS $\left(36.5^{\circ} \pm 30.6^{\circ}\right)$ was significantly different from baseline and pre-AS $(p<0.05)$. No significant difference was noted between pre-S $\left(27.0^{\circ} \pm\right.$ $\left.29.1^{\circ}\right)$ and post-S $\left(28.7^{\circ} \pm 27.1^{\circ}\right)$ but both were significantly different from baseline $(p<0.05)$. Only two subjects had observable active extensional motion in the index finger of the affected upper limb. The mean change in the extension ROM for these two subjects was $30^{\circ}$ after the combined treatment and $0^{\circ}$ after the strength training alone.

The accumulated FM upper-limb sensorimotor score increased in eight subjects, remained the same in one subject, and decreased in one subject after the combined treatment (Figure 3(a)). After the strengthening treatment alone, FM scores of five subjects increased; the other five subjects' FM scores decreased (Figure 3(b)). No significant difference was noted between baseline (26.5 \pm 12.2$)$ and pre-AS (27.6 \pm 11.8 ), but a significant difference was found between pre-AS and post-AS $(32.5 \pm 11.9)(p<$ 0.05 ). No significant difference was noted between pre-S (29.5 \pm 13.3$)$ and post-S (30.2 \pm 12.3$)$ but both were significantly different from baseline $(p<0.05)$.

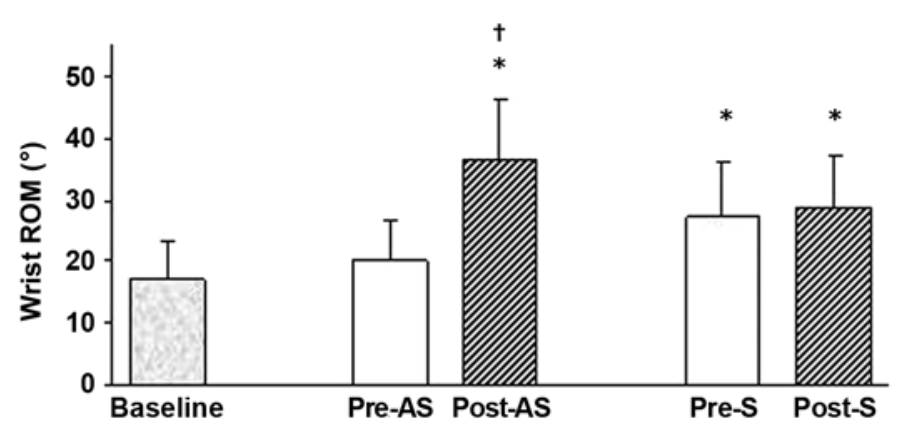

Figure 2.

Active wrist extension range of motion (ROM) (mean \pm standard error of the mean) at baseline and before and after each treatment phase. Baseline value was mean of first measurements of all subjects. Pre-AS and post-AS were mean of measurements of all subjects before and after combined acupuncture and strength training treatment (AS). Pre$\mathrm{S}$ and post-S were mean of measurements of all subjects before and after strengthening treatment (S) alone. *Significant difference from baseline $(p<0.05)$. ${ }^{\dagger}$ Significant difference from pre-AS $(p<0.05)$. 

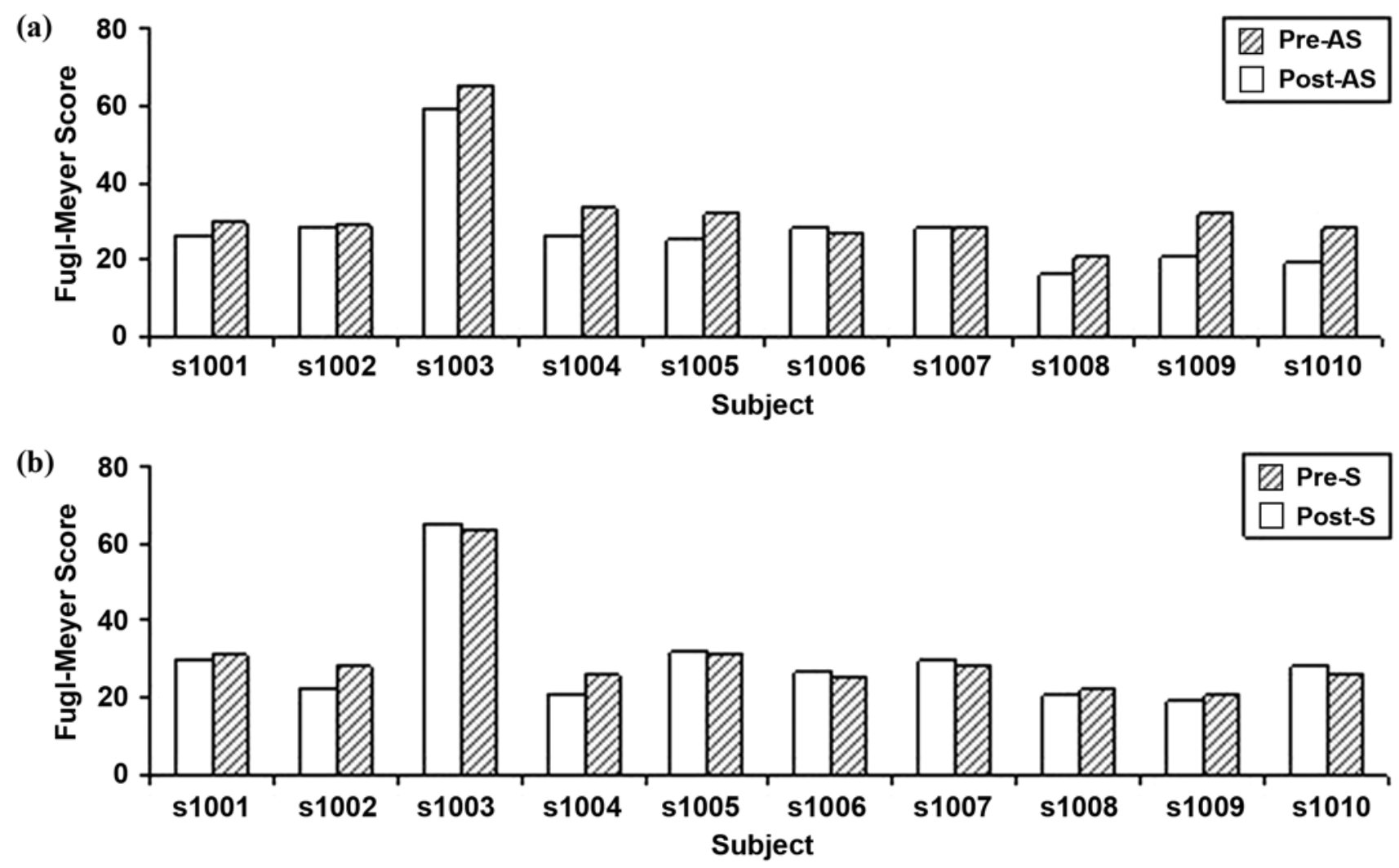

Figure 3.

Accumulated Fugl-Meyer sensorimotor score for upper limb of each subject before and after each treatment phase. After (a) combined acupuncture and strength training treatment (AS), score increased in eight subjects, remained same in one subject, and decreased in one subject. After (b) strengthening alone (S), scores increased in five subjects and decreased in remaining five.

Wrist joint flexion strength at $20^{\circ}$ of wrist flexion showed a small insignificant increase from $1.8 \mathrm{~N} \cdot \mathrm{m}$ before to $2.6 \mathrm{~N} \cdot \mathrm{m}$ after the strength training $(p=0.33)$ and no change at $2.3 \mathrm{~N} \cdot \mathrm{m}$ both before and after the combined treatment. At $20^{\circ}$ of wrist flexion, only small changes in wrist extension strength were observed in the four subjects despite the treatment; therefore, no statistical analysis was conducted for changes in wrist extension strength. Mean extension strength in those four subjects was $0.3 \mathrm{~N} \cdot \mathrm{m}$ before and $0.5 \mathrm{~N} \cdot \mathrm{m}$ after the combined treatment and $0.4 \mathrm{~N} \cdot \mathrm{m}$ before and $0.3 \mathrm{~N} \cdot \mathrm{m}$ after the strength training alone. Similar results were found for wrist strength at the neutral wrist position.

\section{DISCUSSION}

A decrease in spasticity and increases in joint ROM and FM upper-limb scores were found in a group of chronic stroke survivors after combined treatment with electroacupuncture and strengthening exercise. In comparison, the strengthening exercise alone did not show any significant changes in those measurements. This result indicates that acupuncture may be effective not only at reducing muscle spasticity but also at improving motor function in stroke survivors. Several previous studies have shown the benefit of acupuncture for motor improvement in stroke rehabilitation [1-7]. However, the effectiveness of acupuncture on motor functional recovery has been seriously challenged by the results reported in recent clinical trials [8-11]. In the current study, we targeted stroke survivors with moderate to severe muscle spasticity in the affected wrist joint. Our results in the present study are promising. Acupuncture treatment reduced spasticity and offered additional benefits of functional motor recovery when combined with strengthening exercises. Future studies with larger numbers of participants will be required to further confirm this pilot finding. 
The difference in the measurement between the two treatments supported the main finding of the study. The random order in this crossover design resulted in six subjects starting with the combined treatment and the rest of the subjects $(n=4)$ with the strengthening alone. For the wrist extension ROM and FM upper-limb motor score measurements (Figures 2-3), the mean value before the combined treatment was not different from the baseline value. However, the mean value before the strengthening treatment alone was significantly different from the baseline value. This difference suggests that those six subjects who first went through the combined treatment had significantly changed their motor scores.

The improved motor function in the current study was the result of the combination of acupuncture treatment and strengthening exercises. The results from the $\mathrm{S}$ phase showed that strengthening alone did not change the motor function of the subjects. The subjects were all chronic stroke survivors at a minimum of 2 years poststroke (average 7.6 years) (Table). All of them had reached a plateau in their motor functional recovery prior to participating in the study. We were therefore not surprised that conventional strengthening exercise brought minimal benefit to their motor function. Furthermore, although not necessarily a result of the current study, the functional motor improvement in the subjects was not likely a direct benefit of acupuncture treatment. Motor recovery after stroke is a motor relearning process that depends strongly on the amount a subject practices [14-17]. Practice is simply defined as performing the same movement(s) repeatedly. Acupuncture was applied to the subjects while they sat and were relaxed without moving the limb under the treatment. Without movement practice, enough stimulation to elicit or promote the cortical reconstruction that is required for motor recovery would probably not have been present. We anticipated during the design phase of the current study that the acupuncture treatment alone would not directly affect the motor recovery. Acupuncture was therefore applied in combination with a strength training program. Furthermore, since the focus of the present study was to observe motor improvements rather than changes in muscle spasticity, combining an intervention such as strengthening exercises with acupuncture treatment made sense. We believe that during the AS phase, the acupuncture treatment reduced muscle spasticity, which in turn enhanced subjects' performance during the motor training tasks and therefore improved their motor function. This hypothesis, of course, needs to be examined further in future studies.
Decreased muscle spasticity in stroke survivors may not necessarily lead to motor functional recovery. Antispastic medications, such as botulinum toxin, have been used successfully to reduce muscle spasticity, but their effects on motor functional improvement are still under debate [3740]. Antispastic medication usually paralyzes the spastic muscle by disrupting the muscle motor-unit pathway. Stroke survivors would have difficulty performing motor training tasks when their muscles were paralyzed. Unlike antispastic medications, acupuncture treatment reduced muscle spasticity without paralyzing the affected muscles. Reduced muscle spasticity without nerve blockage might make it easier for the subjects to perform strength training tasks and thereby improve their motor function.

Motor functional improvement after the combined treatment in the current study showed mainly in the FM scores and active wrist joint ROM but not the isometric wrist strength, even though the strengthening exercise in the current study included the isometric strength training. The literature on muscle strength training or resistance training in stroke rehabilitation has presented mixed results [41-45]. We observed during strength training sessions that most of the subjects attempted maximum effort during isometric maximal contraction trials. However, their efforts were mostly visible in the proximal trunk and shoulder muscles rather than the wrist muscles, even though the instruction was to rotate the handle around the wrist joint. Subjects might have evoked either antagonistic muscles that tightened up the wrist joint or abnormal muscle synergy when making their maximum effort. Our results would, as some past studies did, question the effectiveness of maximal strength training in chronic stroke patients with muscle spasticity.

One of the limitations of the current study was a lack of blinding of the tester to avoid potential bias. Interpretation of the results, especially the clinical scores, requires caution, even though the quantitative spasticity measurements, strengthening exercises, and active joint ROM might be influenced minimally by a tester's bias. Another limitation of the current study is the lack of a control or placebo effect for acupuncture treatment. A sham procedure may be used in future studies. Finally, the clinical significance of the results may be questioned. For instance, the mean change in FM upper-limb motor score (total of 60 points) was 4.9 after the combined treatment. Although statistically significant, the clinical significance of this change is not certain. A 10 percent change in FM motor scores has been suggested to have a 
clinical significance, even though no commonly accepted value for such judgment has been established [46]. Future studies with longer treatment periods may result in larger improvements. Nevertheless, the current pilot study showed promising results in motor functional improvement when acupuncture was combined with a strength training program in a group of chronic stroke survivors within a relatively short time period.

\section{CONCLUSIONS}

In conclusion, the current study showed a significant decrease in muscle spasticity and increases in active ROM of wrist joint and FM upper-limb motor scores after a combined acupuncture treatment and strengthening exercise intervention. The strengthening alone did not show any beneficial effect on the same subjects. It is premature to draw any firm conclusion given the limitations of this pilot study. It is, however, reasonable to state that the results of the current study indicate a hope that acupuncture treatment may improve motor function if combined with a motor training program in chronic stroke survivors with moderate or severe muscle spasticity.

\section{ACKNOWLEDGMENTS}

We would like to thank Dr. Minzhao Huang for conducting some of the acupuncture treatments on the subjects in this study.

This material was based on work partially supported by a research grant from the American Heart Association (grant 0555637Z).

The authors have declared that no competing interests exist.

\section{REFERENCES}

1. Duan G, He J, Zeng Z, Tang Q, Sun S. Comparison of effects of acupuncture on cerebral infarction in different parts. World J Acup-Mox. 1998;8(2):3-7.

2. Hu HH, Chung C, Liu TJ, Chen RC, Chen CH, Chou P, Huang WS, Lin JC, Tsuei JJ. A randomized controlled trial on the treatment for acute partial ischemic stroke with acupuncture. Neuroepidemiology. 1993;12(2):106-13. [PMID: 8232703]
3. Johansson K, Lindgren I, Widner H, Wiklund I, Johansson BB. Can sensory stimulation improve the functional outcome in stroke patients? Neurology. 1993;43(11):2189-92. [PMID: 8232927]

4. Kjendahl A, Sällström S, Osten PE, Stanghelle JK, Borchgrevink CF. A one year follow-up study on the effects of acupuncture in the treatment of stroke patients in the subacute stage: A randomized, controlled study. Clin Rehabil. 1997;11(3):192-200. [PMID: 9360031]

5. Pei J, Sun L, Chen R, Zhu T, Qian Y, Yuan D. The effect of electro-acupuncture on motor function recovery in patients with acute cerebral infarction: A randomly controlled trial. J Tradit Chin Med. 2001;21(4):270-72. [PMID: 12014128]

6. Sällström S, Kjendahl A, Osten PE, Stanghelle JK, Borchgrevink CF. Acupuncture therapy in stroke during the subacute phase. A randomized controlled trial [in Norwegian]. Tidsskr Nor Laegeforen. 1995;115(23):2884-87. [PMID: 7570509]

7. Si QM, Wu GC, Cao XD. Effects of electroacupuncture on acute cerebral infarction. Acupunct Electrother Res. 1998; 23(2):117-24. [PMID: 9789586$]$

8. Gosman-Hedström G, Claesson L, Klingenstierna U, Carlsson J, Olausson B, Frizell M, Fagerberg B, Blomstrand C. Effects of acupuncture treatment on daily life activities and quality of life: A controlled, prospective, and randomized study of acute stroke patients. Stroke. 1998; 29(10):2100-2108. [PMID: 9756589]

9. Johansson BB, Haker E, Von Arbin M, Britton M, Långström G, Terént A, Ursing D, Asplund K; Swedish Collaboration on Sensory Stimulation After Stroke. Acupuncture and transcutaneous nerve stimulation in stroke rehabilitation: A randomized, controlled trial. Stroke. 2001;32(3): 707-13. [PMID: 11239191]

10. Naeser MA, Alexander MP, Stiassny-Eder D, Galler V. Real versus sham acupuncture in the treatment of paralysis in acute stroke patients: A CT scan site lesion study. J Neurol Rehabil. 1992;6(4):163-73.

11. Sze FK, Wong E, Yi X, Woo J. Does acupuncture have additional value to standard poststroke motor rehabilitation? Stroke. 2002;33(1):186-94. [PMID: 11779909]

12. Sze FK, Wong E, Or KK, Lau J, Woo J. Does acupuncture improve motor recovery after stroke? A meta-analysis of randomized controlled trials. Stroke. 2002;33(11):2604-19. [PMID: 12411650]

13. Schmidt RA, Lee TD. Motor control and learning: A behavioral emphasis. 3rd ed. Champaign (IL): Human Kinetics; 1999.

14. Jenkins WM, Merzenich MM, Ochs MT, Allard T, GuícRobles E. Functional reorganization of primary somatosensory cortex in adult owl monkeys after behaviorally controlled tactile stimulation. J Neurophysiol. 1990;63(1):82-104.

[PMID: 2299388] 
15. Nudo RJ, Wise BM, SiFuentes F, Milliken GW. Neural substrates for the effects of rehabilitative training on motor recovery after ischemic infarct. Science. 1996;272(5269): 1791-94. [PMID: 8650578]

16. Pons TP, Garraghty PE, Ommaya AK, Kaas JH, Taub E, Mishkin M. Massive cortical reorganization after sensory deafferentation in adult macaques. Science. 1991;252(5014): 1857-60. [PMID: 1843843]

17. Recanzone GH, Jenkins WM, Hradek GT, Merzenich MM. Progressive improvement in discriminative abilities in adult owl monkeys performing a tactile frequency discrimination task. J Neurophysiol. 1992;67(5):1015-30. [PMID: 1597695]

18. Alexander DN, Cen S, Sullivan KJ, Bhavnani G, Ma X, Azen SP; ASAP Study Group. Effects of acupuncture treatment on poststroke motor recovery and physical function: A pilot study. Neurorehabil Neural Repair. 2004;18(4): 259-67. [PMID: 15537996]

19. Guo Z, Zhou M, Chen X, Wang R. Acupuncture methods for hemiplegic spasm. J Tradit Chin Med. 1997;17(4):284-88. [PMID: 10437214]

20. Han JS, Chen XH, Yuan Y, Yan SC. Transcutaneous electrical nerve stimulation for treatment of spinal spasticity. Chin Med J (Engl). 1994;107(1):6-11. [PMID: 8187575]

21. Moon SK, Whang YK, Park SU, Ko CN, Kim YS, Bae HS, Cho KH. Antispastic effect of electroacupuncture and moxibustion in stroke patients. Am J Chin Med. 2003;31(3): 467-74. [PMID: 12943177]

22. Omura Y, Lin TL, Debreceni L, Losco BM, Freed S, Muteki T, Lin CH. Unique changes found on the Qi Gong (Chi Gong) Master's and patient's body during Qi Gong treatment; their relationships to certain meridians \& acupuncture points and the re-creation of therapeutic Qi Gong states by children \& adults. Acupunct Electrother Res. 1989;14(1):61-89. [PMID: 2568074$]$

23. Wong AM, Su TY, Tang FT, Cheng PT, Liaw MY. Clinical trial of electrical acupuncture on hemiplegic stroke patients. Am J Phys Med Rehabil. 1999;78(2):117-22. [PMID: 10088585]

24. Yu Y. Transcutaneous electric stimulation at acupoints in the treatment of spinal spasticity: Effects and mechanism [Chinese]. Zhonghua Yi Xue Za Zhi. 1993;73(10):593-95,637. [PMID: 8313180]

25. Sommerfeld DK, Eek EU, Svensson AK, Holmqvist LW, Von Arbin MH. Spasticity after stroke: Its occurrence and association with motor impairments and activity limitations. Stroke. 2004;35(1):134-39. [PMID: 14684785]

26. Watkins CL, Leathley MJ, Gregson JM, Moore AP, Smith TL, Sharma AK. Prevalence of spasticity post stroke. Clin Rehabil. 2002;16(5):515-22. [PMID: 12194622]

27. Welmer AK, Von Arbin M, Widén Holmqvist L, Sommerfeld DK. Spasticity and its association with functioning and health-related quality of life 18 months after stroke. Cerebrovasc Dis. 2006;21(4):247-53. [PMID: 16446538]

28. Bohannon RW, Andrews AW. Correlation of knee extensor muscle torque and spasticity with gait speed in patients with stroke. Arch Phys Med Rehabil. 1990;71(5):330-33. [PMID: 2327887]

29. Bohannon RW, Larkin PA, Smith MB, Horton MG. Relationship between static muscle strength deficits and spasticity in stroke patients with hemiparesis. Phys Ther. 1987; 67(7):1068-71. [PMID: 3602099]

30. Bourbonnais D, Vanden Noven S. Weakness in patients with hemiparesis. Am J Occup Ther. 1989;43(5):313-19. [PMID: 2655457]

31. Sunderland A, Tinson D, Bradley L, Hewer RL. Arm function after stroke. An evaluation of grip strength as a measure of recovery and a prognostic indicator. J Neurol Neurosurg Psychiatry. 1989;52(11):1267-72. [PMID: 2592969]

32. Wilson DJ, Baker LL, Craddock JA. Functional test for the hemiparetic upper extremity. Am J Occup Ther. 1984; 38(3):159-64. [PMID: 6711667]

33. Bohannon RW. Muscle strength and muscle training after stroke. J Rehabil Med. 2007;39(1):14-20. [PMID: 17225032]

34. Lee HM, Huang YZ, Chen JJ, Hwang IS. Quantitative analysis of the velocity related pathophysiology of spasticity and rigidity in the elbow flexors. J Neurol Neurosurg Psychiatry. 2002;72(5):621-29. [PMID: 11971049]

35. Fugl-Meyer AR, Jääskö L, Leyman I, Olsson S, Steglind S. The post-stroke hemiplegic patient. 1. A method for evaluation of physical performance. Scand J Rehabil Med. 1975; 7(1):13-31. [PMID: 1135616$]$

36. Mukherjee M, McPeak LK, Redford LB, Sun C, Liu W. The effect of electro-acupuncture on spasticity of the wrist joint in chronic stroke survivors. Arch Phys Med Rehabil. 2007;88(2):159-66. [PMID: 17270512]

37. Bakheit AM, Thilmann AF, Ward AB, Poewe W, Wissel J, Muller J, Benecke R, Collin C, Muller F, Ward CD, Neumann C. A randomized, double-blind, placebo-controlled, dose-ranging study to compare the efficacy and safety of three doses of botulinum toxin type A (Dysport) with placebo in upper limb spasticity after stroke. Stroke. 2000; 31(10):2402-6. [PMID: 11022071]

38. Brashear A, Gordon MF, Elovic E, Kassicieh VD, Marciniak C, Do M, Lee CH, Jenkins S, Turkel C; Botox PostStroke Spasticity Study Group. Intramuscular injection of botulinum toxin for the treatment of wrist and finger spasticity after a stroke. N Engl J Med. 2002;347(6):395-400. [PMID: 12167681]

39. Landau WM. Spasticity after stroke: Why bother? Stroke. 2004;35(8):1787-88. [PMID: 15232114]

40. Rousseaux M, Kozlowski O, Froger J. Efficacy of botulinum toxin A in upper limb function of hemiplegic patients. J Neurol. 2002;249(1):76-84. [PMID: 11954872] 
41. De Vreede PL, Samson MM, Van Meeteren NL, Duursma SA, Verhaar HJ. Functional-task exercise versus resistance strength exercise to improve daily function in older women: A randomized, controlled trial. J Am Geriatr Soc. 2005;53(1):2-10. [PMID: 15667369]

42. Inaba M, Edberg E, Montgomery J, Gillis MK. Effectiveness of functional training, active exercise, and resistive exercise for patients with hemiplegia. Phys Ther. 1973; 53(1):28-35. [PMID: 4682697]

43. Moreland JD, Goldsmith CH, Huijbregts MP, Anderson RE, Prentice DM, Brunton KB, O’Brien MA, Torresin WD. Progressive resistance strengthening exercises after stroke: A single-blind randomized controlled trial. Arch Phys Med Rehabil. 2003;84(10):1433-40. [PMID: 14586909]

44. Weiss A, Suzuki T, Bean J, Fielding RA. High intensity strength training improves strength and functional per- formance after stroke. Am J Phys Med Rehabil. 2000;79(4): 369-76. [PMID: 10892623]

45. Winstein CJ, Rose DK, Tan SM, Lewthwaite R, Chui HC, Azen SP. A randomized controlled comparison of upperextremity rehabilitation strategies in acute stroke: A pilot study of immediate and long-term outcomes. Arch Phys Med Rehabil. 2004;85(4):620-28. [PMID: 15083439]

46. Gladstone DJ, Danells CJ, Black SE. The Fugl-Meyer assessment of motor recovery after stroke: A critical review of its measurement properties. Neurorehabil Neural Repair. 2002;16(3):232-40. [PMID: 12234086]

Submitted for publication November 6, 2007. Accepted in revised form December 19, 2007. 